\title{
Opposite-base dependent excision of 5-formyluracil from DNA by hSMUG1
}

\author{
INGEBORG KNÆVELSRUD ${ }^{1}$, GEIR SLUPPHAUG ${ }^{2}$, INGAR LEIROS ${ }^{3}$, AKIRA MATSUDA $^{4}$, \\ PETER RUOFF ${ }^{1}$, \& SVEIN BJELLAND ${ }^{1}$ \\ ${ }^{1}$ Faculty of Science and Technology, Department of Mathematics and Natural Sciences, University of Stavanger, Stavanger, \\ Norway, ${ }^{2}$ Department of Cancer Research and Molecular Medicine, Norwegian University of Science and Technology, \\ Trondheim, Norway, ${ }^{3}$ The Norwegian Structural Biology Centre (Norstruct), Department of Chemistry, University of Tromsø, \\ Tromsø, Norway, and ${ }^{4}$ Graduate School of Pharmaceutical Sciences, Hokkaido University, Sapporo, Fapan
}

(Received 9 April 2008; Revised 27 fanuary 2009; Accepted 29 fanuary 2009)

\begin{abstract}
Purpose: The aim of this study was to determine the excision efficiency of hSMUG1 (human single-strand-selective monofunctional uracil-DNA glycosylase) for 5-formyluracil (fU), a major thymine lesion formed by ionizing radiation, opposite all normal bases in DNA, to possibly explain mutation induction by $\mathrm{fU}$ in the DNA of mammalian cells.

Materials and methods: An enzymatically $\left[{ }^{32} \mathrm{P}\right]$ labelled fU-containing 36 nucleotide DNA sequence plus its complementary sequence (with an $\mathrm{A}, \mathrm{C}, \mathrm{G}$ or $\mathrm{T}$ residue inserted opposite $\mathrm{fU}$ ) was subjected to hSMUG1 in a $\mathrm{pH}$ 7.5-buffer, followed by $\mathrm{NaOH}-$ mediated cleavage of the resultant abasic sites. Cleaved and uncleaved DNA were separated by denaturing electrophoresis and quantified by autoradiography.

Results: The hSMUG1 excised fU from DNA opposite all normal bases with the highest activity when opposite noncognate $\mathrm{C}$ or $\mathrm{T}$ followed by $\mathrm{G}$ and cognate $\mathrm{A}$.

Conclusions: The predominant $\mathrm{T} \rightarrow \mathrm{G}$ and $\mathrm{T} \rightarrow \mathrm{A}$ transversions induced by $\mathrm{fU}$ in mammalian cells may be explained by replicative incorporation of $\mathrm{C}$ and $\mathrm{T}$, respectively, opposite the lesion and subsequent SMUG1-initiated repair of fU.
\end{abstract}

Keywords: Reactive oxygen species, DNA damage, DNA repair, mutation

\section{Introduction}

In the electron transport chain of mitochondria as well as at other locations in aerobic cells reactive oxygen species (ROS) are formed as toxic byproducts, reacting with a multitude of molecules including DNA. In addition, ROS are formed by ionizing radiation and photosensitization reactions involving both ultraviolet and visible light (Halliwell and Gutteridge 1989). 5-Formyluracil (fU) is an abundant ROS-formed thymine product both detected in DNA in vitro (Kasai et al. 1990, Douki et al. 1996) as well as in cellular DNA (Pouget et al. 2002, Hong and Wang 2007), acting mainly as a mutagenic lesion if not repaired, primarily by the base excision repair (BER) pathway (Bjelland and Seeberg 2003). BER is initiated by a DNA glycosylase leaving behind an abasic (AP) site. The AP site can subsequently be removed and replaced by a correct nucleotide by the sequential action of 5'-acting AP endonuclease, DNA deoxyribophosphodiesterase, DNA polymerase and DNA ligase (Lindahl and Wood 1999, Slupphaug et al. 2003). The principal fU glycosylase activity was first characterized in Escherichia coli (Bjelland et al. 1994), and a decade later identified in mammalian cells as a function of the SMUG1 (single-strandselective monofunctional uracil-DNA glycosylase 1) protein (Masaoka et al. 2003, Matsubara et al. 2003). In addition, human NTH1 (endonuclease III homologue 1) and MBD4 (methylated DNA-binding domain protein 4) and mouse Tdg (mismatchspecific thymine-DNA glycosylase) proteins, as well as the human nucleotide excision repair complex,

Correspondence: Svein Bjelland, Faculty of Science and Technology, Department of Mathematics and Natural Sciences, University of Stavanger, N-4036 Stavanger, Norway. Tel: +47 51831884. Fax: +47 51831750. E-mail: svein.bjelland@uis.no 
have been found to exhibit activity for fU in DNA in vitro (Miyabe et al. 2002, Liu et al. 2003, Kino et al. 2004).

Largely, fU induces different DNA base substitutions, but the nature of these seems different in bacteria and mammalian cells (Fujikawa et al. 1998, Ånensen et al. 2001, Kamiya et al. 2002). In the present report we describe the opposite-base dependent removal of fU from DNA by hSMUG1 protein, and suggest how this may explain the spectrum of mutations induced in mammalian cells as compared to bacteria.

\section{Materials and methods}

\section{Enzymes}

Human SMUG1 and UNG2 (uracil-N-glycosylase 2) proteins were purified to apparent physical homogeneity as described (Kavli et al. 2002). Human OGG1 (8-oxoguanine-DNA glycosylase 1) protein was a gift from Dr M. Bjørås (Bjørås et al. 1997).

Enzymatic cleavage of a DNA fragment containing a $\mathrm{fU}$ residue inserted at a specific position

The fU-containing 10 nucleotide (nt) DNA sequence $5^{\prime}$-GGAGAfUCTCC- ${ }^{\prime}$ was prepared as described (Ono et al. 1994) and phosphorylated using T4 polynucleotide kinase and $\left[\gamma^{32} \mathrm{P}\right] \mathrm{ATP}$ (Amersham Biosciences Europe $\mathrm{GmbH}$, Freiburg, Germany) (fU-oligo). All additional oligonucleotides were provided by MedProbe/Eurogentec S.A. The fU-oligo was annealed to a complementary sequence [with an $\mathrm{A}, \mathrm{C}, \mathrm{G}$ or $\mathrm{T}$ residue $(=\mathrm{X})$ inserted opposite $\mathrm{fU}]$ being the middle part of a $36 \mathrm{nt}$ oligonucleotide (3'-AACTGTAACGGGACCTCT XGAGGATCTGCTTAAGGG-5'), together with two other oligonucleotides complementary to the rest of the $36 \mathrm{nt}$ oligonucleotide, followed by treatment with T4 DNA ligase. The final radiolabelled substrate was purified on a $20 \%$ (w/v) denaturing ( $7 \mathrm{M}$ urea) polyacrylamide gel. The glycosylase reactions with purified enzymes were performed in $20 \mu \mathrm{l}$ of $70 \mathrm{mM}$ MOPS [3- $(\mathrm{N}-$ morpholino)propanesulphonic acid], $\mathrm{pH}$ 7.5, $1 \mathrm{mM}$ ethylenediaminetetraacetic acid (EDTA), $1 \mathrm{mM}$ dithiothreitol, 5\% (v/v) glycerol (reaction buffer) as described under Results, followed by the addition of $0.1 \mathrm{M} \mathrm{NaOH}(20 \mu \mathrm{l})$ and incubation at $90^{\circ} \mathrm{C}$ for $30 \mathrm{~min}$. Following centrifugation, formamidecontaining loading buffer $(20 \mu \mathrm{l})$ was added to each sample, the mixtures incubated at $100^{\circ} \mathrm{C}$ for $3 \mathrm{~min}$ and stored on ice. Each sample $(7 \mu \mathrm{l})$ was subjected to electrophoresis on a $20 \%(\mathrm{w} / \mathrm{v})$ polyacrylamide/7 $\mathrm{M}$ urea gel to separate cleaved from uncleaved
DNA. Visualization and quantification were performed by autoradiography using $\mathrm{Kodak}^{\mathrm{TM}}$ $\mathrm{X}^{-O M A T}{ }^{\mathrm{TM}}$ Blue Film (NEN \#NEF596; PerkinElmer Norge AS, Oslo, Norway) which was analyzed on a Gel Doc 2000 apparatus (Bio-Rad Laboratories, USA), where per cent cleavage was determined using GeneSnap and GeneTools softwares (Syngene, Cambridge, UK). The amount of product formed (see Figure 1C) was calculated from per cent cleavage of the substrate DNA added (see Figure 1B; $0.64 \mathrm{fmol}$ ), which divided by the incubation time results in the reaction rate $v$ (see next section).

\section{Kinetic and data analysis}

The kinetic model used in this study describes processing of a substrate DNA by the enzyme E leading to the cleavage product $\mathrm{P}$ :

$$
\mathrm{DNA} \stackrel{k}{\longrightarrow} \mathrm{P}
$$

Reaction rate $v$ and first-order rate constant $k$ of process R1 are expressed by Equation 1:

$$
v=-\frac{d[\mathrm{DNA}]}{d t}=\frac{d[\mathrm{P}]}{d t}=k[\mathrm{DNA}]
$$

In case the enzyme is in excess over DNA, reaction rate $v$ is expressed by:

$$
v=k_{c a t} \frac{[\mathrm{E}]_{t o t}[\mathrm{DNA}]}{K_{D}+[\mathrm{E}]_{t o t}}
$$

where $k_{c a t}$ is the turnover number and the subscript tot refers to the total enzyme concentration. $K_{D}$ can be interpreted as a rapid equilibrium constant between free and enzyme-bound substrate or as a steady state constant. Derivation and discussion of Equation 2 are presented elsewhere (Leiros et al. 2007).

In order to determine $k_{c a t}$ and $K_{D}, k$ is first determined from enzymatic cleavage experiments as $v /[\mathrm{DNA}]$ (Equation 1) with $v$ as the amount of cleaved substrate $(\mathrm{nM})$ per time unit $(\mathrm{min})$ and where [DNA] refers to its initial concentration. From Equations 1 and $2 k$ is expressed by:

$$
k=k_{c a t} \frac{[\mathrm{E}]_{t o t}}{K_{D}+[\mathrm{E}]_{t o t}}
$$

Experimentally determined $k$ values as a function of $[\mathrm{E}]_{t o t}$ were fitted to Equation 3 using the program KaleidaGraph (www.synergy.com). Good agreements between experimental results and the model equations were obtained (see Figure 1D). From the 
a)

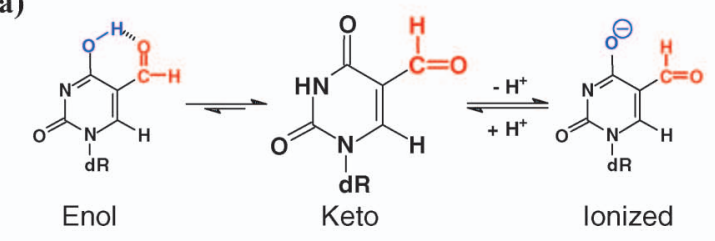
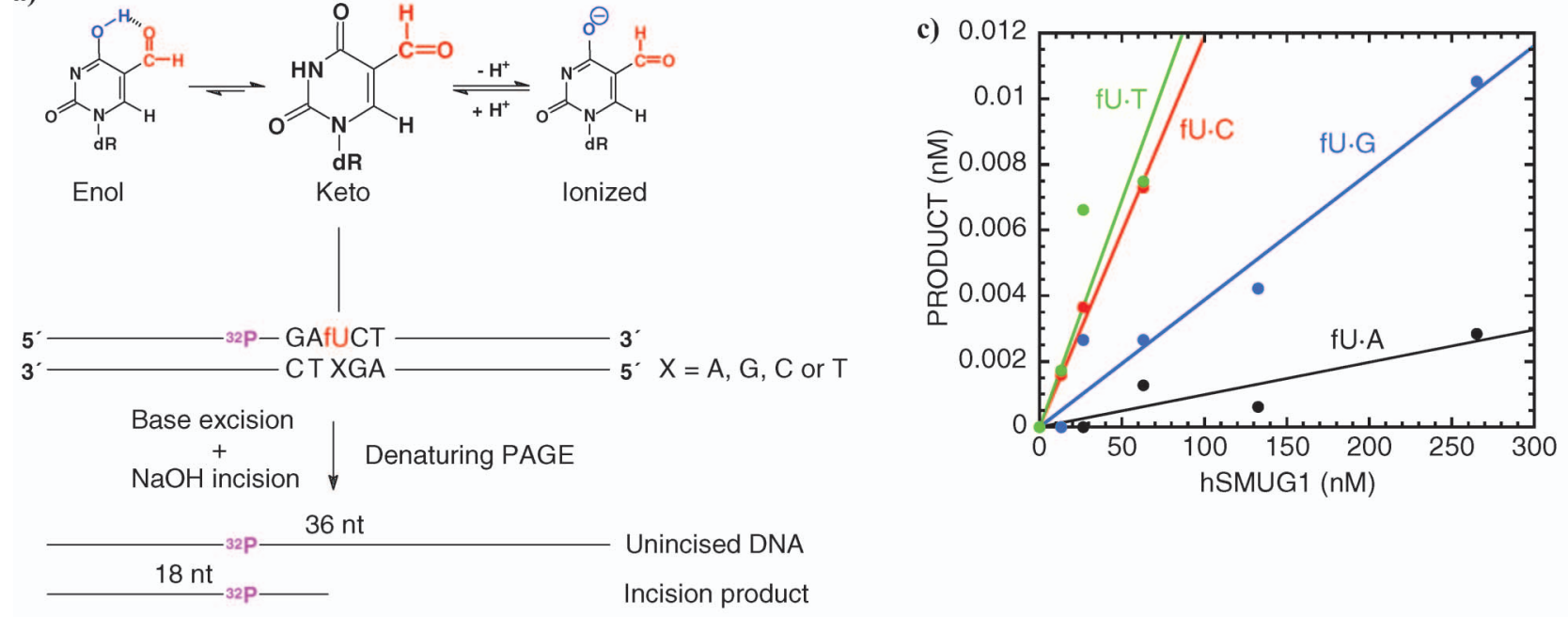

b)
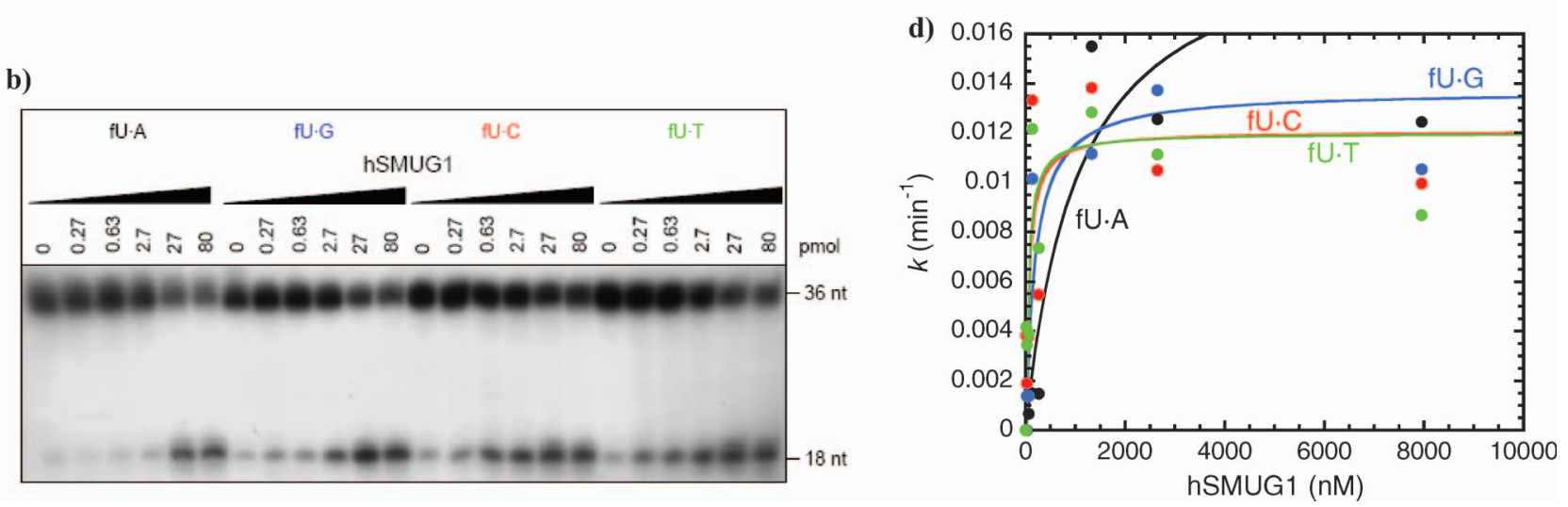

Figure 1. Opposite-base dependent excision of fU from DNA by hSMUG1. (A) The oligonucleotides containing fU at a specific position utilized as substrates. The size of the incision product following glycosylase excision of the specified base lesion and base-catalyzed phosphodiester bond cleavage of the resulting abasic site by alkali treatment is indicated. (B) Cleavage of $\left[{ }^{32} \mathrm{P}\right]$ labelled $36 \mathrm{nt}$ DNA into $18 \mathrm{nt}$ repair product is shown for a typical experiment. Enzyme $(0-80 \mathrm{pmol})$ was incubated with substrate (0.64 fmol; upper bands), only differing by containing a different base opposite $\mathrm{fU}$ as indicated, in $10 \mu \mathrm{l}$ reaction buffer at $37^{\circ} \mathrm{C}$ for $30 \mathrm{~min}$. (C) The linear range of product formation as a function of protein concentration based on four independent experiments. (D) Calculated $k$ values as a function of [E] tot together with a curve fit of Equation 3 to the experimental data (see Results section).

fit estimates, $k_{c a t}$ and $K_{D}$ values were obtained for the different substrates (see Table I).

\section{Homology modelling of hSMUG1}

Homology modelling of the structure of hSMUG1 was based on the previously determined crystal structure of SMUG1 from Xenopus laevis (xSMUG1) (Wibley et al. 2003). The sequence identity between the two protein homologues is $65 \%$ for the modelled region comprising residues $38-280$ and $27-269$ for xSMUG1 and hSMUG1, respectively. The sequences align without insertions or deletions; therefore, the structure of hSMUG1 was modelled by direct threading of the hSMUG1 sequence onto the xSMUG1 structure using SwissPDBViewer (Guex and Peitsch 1997). Within the SMUG1 substratebinding pocket and DNA-interacting wedge-motif,
Table I. Kinetic parameters for the opposite-base dependent excision of fU from DNA by hSMUG1.

\begin{tabular}{lccl}
\hline $\begin{array}{l}\text { Opposite } \\
\text { base }\end{array}$ & $k_{\text {cat }} \min ^{-1}$ & $K_{D} \mathrm{nM}$ & $\begin{array}{c}k_{\text {cat }} / K_{D} \min ^{-1} / \\
\mathrm{nM} \text { (fold) }\end{array}$ \\
\hline $\mathrm{A}$ & $0.021 \pm 0.007$ & $1100 \pm 900$ & $0.00002(1)$ \\
$\mathrm{G}$ & $0.014 \pm 0.002$ & $200 \pm 100$ & $0.00007(3.5)$ \\
$\mathrm{C}$ & $0.012 \pm 0.002$ & $70 \pm 50$ & $0.00018(9)$ \\
$\mathrm{T}$ & $0.012 \pm 0.002$ & $50 \pm 30$ & $0.00022(11)$ \\
\hline
\end{tabular}

Errors indicate the standard error of the mean (SEM) for $n=4$ independent experiments.

there are no sequence discrepancies. The crystal structure of xSMUG1 with uracil soaked into the substrate-binding pocket (Wibley et al. 2003) was used as template for modelling of the hSMUG1uracil- and hSMUG1-fU-interactions. 


\section{Results}

To analyze the efficiency of $\mathrm{fU}$ excision from the $\mathrm{fU}$. A match and the different mismatches of the $\mathrm{fU}$ base, a certain amount of a defined DNA sequence with $\mathrm{fU}$ inserted at a specific position (Figure 1A) was used as substrate for hSMUG1. To avoid interference from less well-defined factors such as possible product inhibition (released base; AP-site) and enzyme inactivation, activity was measured using enzyme in excess of substrate (Leiros et al. 2007). As opposed to the controls without enzyme, $\mathrm{NaOH}-$ mediated cleavage of all four substrate duplexes was observed in the presence of hSMUG1 irrespective of the base opposite fU (Figure 1B). However, the fU excision efficiency was highly dependent on the opposite base (Figure 1C), as the reaction with the $\mathrm{fU} \cdot \mathrm{C}$ and $\mathrm{fU} \cdot \mathrm{T}$ oligomers proceeded $>10$ times faster than the reaction with the $\mathrm{fU} \cdot$ A oligomer, and an intermediate rate was observed with the $\mathrm{fU} \cdot \mathrm{G}$ oligomer. The first order rate constant $k$, which describes the overall accumulation of product during the excision, is presented in Figure 1D, indicating that hSMUG1 excises fU opposite noncognate $\mathrm{C}, \mathrm{T}\left(k_{\text {cat }}=0.012 \pm 0.002 \mathrm{~min}^{-1}\right)$ and $\mathrm{G}$ $\left(k_{\text {cat }}=0.014 \pm 0.002 \mathrm{~min}^{-1}\right)$ half as fast as opposite cognate A $\left(k_{\text {cat }}=0.021 \pm 0.007 \mathrm{~min}^{-1}\right)$ (Table I). However, due to a significantly higher $K_{D}$, the $k_{c a t} /$ $K_{D}$ values indicate that the $\mathrm{fU} \cdot \mathrm{C}$ and $\mathrm{fU} \cdot \mathrm{T}$ substrates are cleaved four times more efficiently than the $\mathrm{fU} \cdot \mathrm{G}$ substrate and 10 times more efficiently than the fU . A substrate (Table I). We also incubated all four oligomers with identical amounts (in pmol) of hUNG2 and hOGG1 proteins under the same conditions as for hSMUG1, resulting in no cleavage in any context of base-pairing (data not shown).

Furthermore, we have performed homology modelling of hSMUG1 based on the crystal structure of $X$. laevis SMUG1 (Wibley et al. 2003), indicating that both uracil and $\mathrm{fU}$ form relatively strong and specific interactions in the substrate-binding pocket. While a water molecule forms hydrogen bonds to the main-chain nitrogens of Gly87 and Met91 in the uracil-protein complex (Figure 2A), the formyl group of $\mathrm{fU}$ replaces this water molecule and its interactions (Figure 2B). By inspecting both the homology model of hSMUG1 overlaid onto the crystal structure of the complex formed between xSMUG1 and double-stranded DNA (PDB entry 1OE5) previously determined (Wibley et al. 2003), no sequence-specific interactions nearer than about $9.5 \AA$ with nucleotides in the complementary strand could be observed in any of the two SMUG1s (data not shown), suggesting that the differences in fU excision efficiency between the different opposite bases (Table I) solely are due to differences in base a)
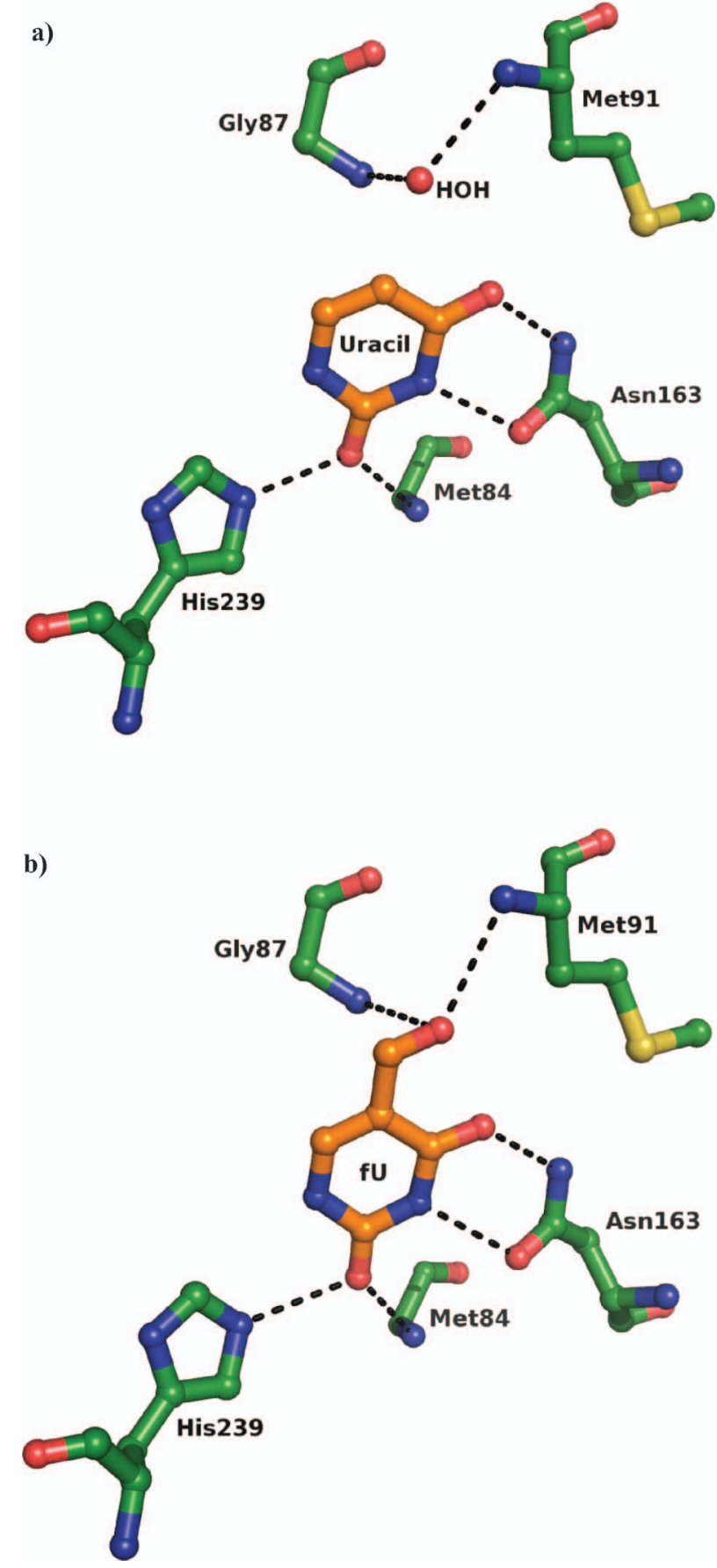

Figure 2. The substrate-binding pocket of hSMUG1 and its interactions with uracil (A) and $\mathrm{fU}$ (B). Protein residues are shown in ball-and-stick representations. Carbon atoms are coloured green in protein and orange in DNA base analogue. Hydrogen bond interactions are indicated with black dashed lines. For clarity, the $\pi-\pi$ stacking interaction formed between the base and Phe98 has been omitted, as well as the side-chain of Met84.

pair stability (Figure 3). As indicated above, this accords with the efficiency by which hSMUG1 removes damaged bases from single-stranded DNA (Kavli et al. 2002, Masaoka et al. 2003) (Table II). 


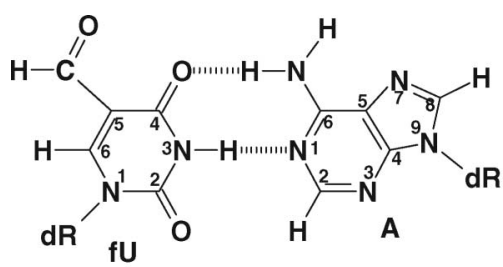<smiles></smiles>

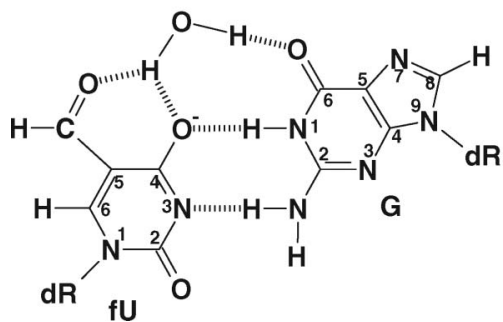<smiles>Cn1cccc(CN2C(=O)NC(C=O)NC2=O)c1=O</smiles>

Figure 3. Postulated base-pairing properties of fU residues in DNA. Cognate base-pairing with adenine is due to the keto form. Conversion from keto to ionized (anionic) form increases with $\mathrm{pH}$ (see Figure 1A) and results in the fU . G mispair presented. Both these base pairs have been demonstrated by X-ray analyses of DNA oligomers with fU inserted at a specific site (Tsunoda et al. 2001, 2002), in contrast to the $\mathrm{fU} \cdot \mathrm{C}$ and $\mathrm{fU} \cdot \mathrm{T}$ mispairs which are tentative (Kamiya et al. 2002).

Table II. Mammalian proteins evaluated for repairing fU in DNA in vitro.

\begin{tabular}{|c|c|c|}
\hline Enzyme & Activity & Reference \\
\hline \multicolumn{3}{|l|}{ Active } \\
\hline hSMUG1 & ${ }_{+}^{\mathrm{CT}>\mathrm{G}>\mathrm{A}, \mathrm{ssDNA}}$ & This report; (Masaoka et al. 2003) \\
\hline rSmug1 & $+{ }^{\mathrm{A}, \mathrm{ssDNA}}$ & (Masaoka et al. 2003) \\
\hline hMBD4 & $+{ }^{\mathrm{G}}{ }_{-}^{\mathrm{A}}$ & (Liu et al. 2003) \\
\hline mTdg & $+{ }^{\mathrm{G}>\mathrm{A}}$ & (Liu et al. 2003) \\
\hline hNTH1 & $+{ }^{\mathrm{GCT}>\mathrm{A}}$ & (Matsubara et al. 2003; Miyabe et al. 2002; Zhang et al. 2005) \\
\hline mNth1 & $+{ }^{\mathrm{A}}$ & (Matsubara et al. 2003) \\
\hline hNEIL1 & $+{ }^{\mathrm{TGC}}>\mathrm{A}, \mathrm{ssDNA}$ & (Katafuchi et al. 2004; Zhang et al. 2005) \\
\hline hNER & $+{ }^{\mathrm{C}>\text { TG_A }}$ & (Kino et al. 2004) \\
\hline \multicolumn{3}{|l|}{ Not active } \\
\hline hNEIL2 & $-{ }^{\mathrm{A}}$ & (Katafuchi et al. 2004) \\
\hline hUNG2 & AG & This report \\
\hline hOGG1 & -AG & This report; (Matsubara et al. 2003) \\
\hline hMPG & ${ }^{\mathrm{A}}$ & (Masaoka et al. 1999; Matsubara et al. 2003) \\
\hline $\mathrm{mMpg}$ & ${ }^{\mathrm{A}}$ & (Matsubara et al. 2003) \\
\hline
\end{tabular}

The opposite base(s) is(are) indicated in superscript(s); h, human; MPG, methylpurine-DNA glycosylase; m, mouse; NEIL1/2, endonuclease VIII-like 1/2; NER, nucleotide excision repair; $r$, rat; ss, single-stranded; +, cleavage/excision; -, no cleavage/excision (detected on oligonucleotides with $\mathrm{fU}$ inserted at a specific position).

\section{Discussion}

Previous work has shown that mammalian SMUG1 excises fU from both single- and double-stranded DNA (Table II) and exhibits 1.9-fold higher activity when $\mathrm{fU}$ is placed opposite $\mathrm{G}$ compared to A (Masaoka et al. 2003, Matsubara et al. 2003). Using a similar amount of enzyme compared to substrate and DNA of similar length we here demonstrate the efficiency by which hSMUG1 removes fU from double-stranded DNA in all contexts of base-pairing, including opposite $\mathrm{C}$ and $\mathrm{T}$ (Figure 1C). The results show that hSMUG1 excises fU opposite non-cognate
$\mathrm{C}$ and $\mathrm{T} 4$ times more efficiently than opposite non-cognate $G$ and 10 times more efficiently than opposite cognate A (Table I). This accords with our homology modelling of the hSMUG1-uracil and hSMUG1-fU complexes showing no apparent interactions with the complementary (see Results section) as opposed to the damage-containing strand (Figure 2A, 2B), suggesting that the differences in $\mathrm{fU}$ excision efficiency opposite different bases (Figure 3) largely are determined by the ease by which the enzyme may flip-out the $\mathrm{fU}$ base into the substratebinding pocket (Figure 2B). Our results thus agree with the widely accepted flipping-out mechanism for DNA glycosylase action where the enzyme has 
to disrupt the base-pairing and base-stacking interactions of $\mathrm{fU}$ in double-stranded DNA to be accommodated in the active site pocket (McCullough et al. 1999, Wibley et al. 2003). The interactions with both uracil and $\mathrm{fU}$ were compared, showing that in order for $\mathrm{fU}$ to be accepted into the substrate-binding pocket of hSMUG1, a water molecule has to be replaced (Figure 2A, 2B). This has also been indicated earlier (Matsubara et al. 2004), where the chemical character of some of the substrates was examined and sketched out as twodimensional projections.

Other mammalian proteins than SMUG1 have also been found to harbour activity towards $\mathrm{fU}$ in DNA in vitro. A fU-releasing activity working in all contexts of base-pairing was recently demonstrated to be a function of the hNTH1 protein (Miyabe et al. 2002) (Table II). The enzymatic efficiency seems to be similar to that of hSMUG1, indicating that hNTH1 may be equally important as hSMUG1 in the excision of $\mathrm{fU}$ from cellular DNA in mammals. However, the importance of hNTH1 as a mammalian fU DNA glycosylase has been challenged by another study (Masaoka et al. 2003), showing that antibodies directed against hSMUG1 effected complete inhibition of the activity for $\mathrm{fU}$ opposite A present in HeLa cell extracts. In addition, the hNTH1 protein investigated by the former study was truncated by lacking 22 residues at the N-terminus, exhibiting a much higher activity than full-length hNTH1. Using HeLa nuclear extract, excision of $\mathrm{fU}$ opposite $\mathrm{G}$ in DNA was observed to be 10 times more efficient than opposite A (Liu et al. 2003). This can, at least in part, be explained by the different kinetics of excision of $\mathrm{fU}$ paired with $\mathrm{G}$ compared to A shown by hSMUG1 (Table I). This also conforms to the observed preference of SMUG1 for uracil opposite G rather than opposite A (Kavli et al. 2002) which has been suggested to be inflicted by a wedge motif in hSMUG1 that makes specific contacts with guanine opposite the lesion (Pettersen et al. 2007), although from our homology modelling and visualization of the crystal structure of $x S M U G 1$ in complex with double-stranded DNA, no such sequence-specific contacts closer than about $9.5 \AA$ can be observed between residues in the wedge-motif of the protein and guanine opposite the lesion. In addition, mammalian TDG and MBD4 proteins may contribute to the excision of $\mathrm{fU}$ from DNA when opposite G but exhibit very low or no activity, respectively, when opposite A (Liu et al. 2003). hNEIL1 as opposed to hNEIL2 also exhibits some activity for fU in DNA (Katafuchi et al. 2004, Zhang et al. 2005) (Table II). Also interesting, the human nucleotide excision repair system excises $\mathrm{fU}$ most efficiently opposite C exhibiting lower activity opposite $\mathrm{T}$ followed by $\mathrm{G}$, and with very low or no activity opposite A (Kino et al. 2004) (Table II).

Although fU primarily behaves like thymine forming a stable Watson-Crick base pair with adenine (Bjelland et al. 1995, Tsunoda et al. 2002, Volk et al. 2007), it can also make a stable ionized reversed wobble base pair with guanine, as demonstrated by X-ray analyses of double-stranded DNA oligomers with $\mathrm{fU}$ inserted at a specific position (Tsunoda et al. 2001) (Figure 3). This establishes a structural basis for the frequent induction of $\mathrm{A} \cdot \mathrm{T} \rightarrow \mathrm{G} \cdot \mathrm{C}$ and $\mathrm{G} \cdot \mathrm{C} \rightarrow \mathrm{A} \cdot \mathrm{T}$ transitions by this lesion in $E$. coli (Fujikawa et al. 1998, Ånensen et al. 2001). In addition, the frequent induction of $\mathrm{G} \cdot \mathrm{C} \rightarrow \mathrm{T} \cdot \mathrm{A}$ and less frequent induction of $\mathrm{A} \cdot \mathrm{T} \rightarrow \mathrm{C} \cdot \mathrm{G}$ and $\mathrm{A} \cdot \mathrm{T} \rightarrow \mathrm{T} \cdot \mathrm{A}$ transversions in $E$. coli provide indirect evidence that $\mathrm{fU}$ also base-pairs with cytosine and thymine, although not yet confirmed by X-ray or nuclear magnetic resonance analyses. Clearly, the $\mathrm{G} \cdot \mathrm{C} \rightarrow \mathrm{A} \cdot \mathrm{T}$ and $\mathrm{G} \cdot \mathrm{C} \rightarrow \mathrm{T} \cdot \mathrm{A}$ mutations arise from incorporation of 5-formyl-2'-deoxyuridine 5 -monophosphate into DNA via the damaged polymerase substrate 5-formyl-2'-deoxyuridine 5'-triphosphate (fdUTP) rather than initial template DNA containing fU. However, in vitro replication studies have shown that template fU directs incorporation of dCMP in addition to dAMP in DNA (Zhang et al. 1997). Two tentative mispairs between $\mathrm{C} / \mathrm{T}$ and $\mathrm{fU}$ involving the formyl group in hydrogen bonding (Figure 3) can explain the higher ability of fU compared to thymine itself to mispair with $\mathrm{C}$ and $\mathrm{T}$ (Kamiya et al. 2002). Also, a putative $\mathrm{T} \cdot \mathrm{T}$ or $\mathrm{T}$. C mispair formed during replication would not be fixed by SMUG1 or other known enzymes (see Figure 4): If not removed by a polymerase $3^{\prime} \rightarrow 5^{\prime}$ exonuclease activity they would be efficiently removed by postreplicative mismatch repair (Genschel et al. 1998).

However, the structural studies cannot explain the observations showing that the nature of the fUinduced base substitutions is quite different in $E$. coli compared to mammalian cells. While $\mathrm{A} \cdot \mathrm{T} \rightarrow \mathrm{G} \cdot \mathrm{C}$, $\mathrm{G} \cdot \mathrm{C} \rightarrow \mathrm{A} \cdot \mathrm{T}$ and $\mathrm{G} \cdot \mathrm{C} \rightarrow \mathrm{T} \cdot \mathrm{A}$ mutations were induced most frequently in $E$. coli following exposure to 5-formyl-2'-deoxyuridine or fdUTP (Fujikawa et al. 1998, Ånensen et al. 2001), A · T $\rightarrow$ C · G and $A \cdot T \rightarrow T \cdot A$ transversions were found to be formed most frequently following transfection of simian COS-7 cells with a fU-containing double-stranded shuttle vector (Kamiya et al. 2002) even though they should be less favoured structurally. In $E$. coli these base substitutions are among the most infrequently formed (Fujikawa et al. 1998, Ånensen et al. 2001). However, the present results describing the oppositebase dependent excision of $\mathrm{fU}$ by hSMUG1, which now should be regarded as the principal fU-DNA 

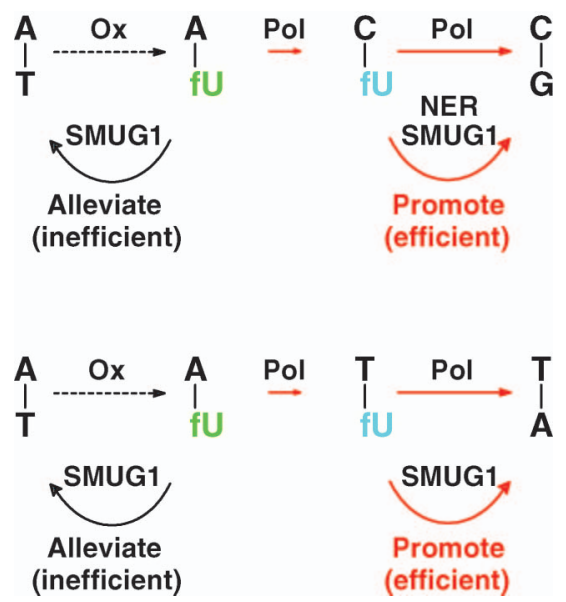

Figure 4. Proposed involvement of SMUG1 DNA glycosylase in promotion of $T \rightarrow G$ and $T \rightarrow A$ transversions induced by $f U$ present in (or incorporated into from the nucleotide pool) the DNA of mammalian cells. The scheme suggests the replicative and repair events leading to mutation induction and alleviation. It should be kept in mind that the most favoured fU-containing base pair is that with adenine suggesting that the $\mathrm{A} \cdot \mathrm{fU} \rightarrow \mathrm{C} \cdot \mathrm{fU}$ and $\mathrm{A} \cdot \mathrm{fU} \rightarrow \mathrm{T} \cdot \mathrm{fU}$ 'transitions' are rare and limiting events in vivo (short arrow, replicative event of low probability; long arrow, replicative event of high probability). Pol, DNA-polymerase; fU, expected relatively high steady state level in DNA; fU, expected very low steady state level in DNA; the major processes contributing to a specific base substitution are indicated by red arrows. It should be noted that the mutations indicated are not specifically alleviated by SMUG1; SMUG1 rather decreases the concentration of $\mathrm{fU}$ in DNA opposite adenine.

glycosylase in mammalian cells, provide a reasonable explanation for this phenomenon.

Notwithstanding that $\mathrm{fU}$ is introduced into cellular DNA - both by in situ oxidation of $\mathrm{T}$ to $\mathrm{fU}$ and by incorporation of oxidized precursors - primarily opposite cognate A (Bjelland et al. 2001), SMUG1 removes fU opposite A inefficiently (Figure 1C). Notably, this also holds true for the other putative enzymes involved in fU removal (Table II). This contrasts with the effective excision of $\mathrm{fU}$ when it becomes, although probably very infrequently, paired with $\mathrm{C}$ and $\mathrm{T}$ during replication (Figure 1C), which should promote induction of $\mathrm{A} \cdot \mathrm{T} \rightarrow \mathrm{C} \cdot \mathrm{G}$ and $\mathrm{A} \cdot \mathrm{T} \rightarrow \mathrm{T} \cdot \mathrm{A}$ transversions (Figure 4). Consequently, the 'unexpected' $\mathrm{T} \rightarrow \mathrm{G}$ and $\mathrm{T} \rightarrow \mathrm{A}$ transversions induced by $\mathrm{fU}$ in mammalian cells can be explained by SMUG1-mediated mutation fixation, dependent on whether excision of $\mathrm{fU}$ occurs prior to or after a transition from the first to a second type of opposite base during DNA replication.

\section{Acknowledgements}

This work was supported by the Research Council of Norway (Grant No. 148997/432). We are indebted to Drs $\mathrm{M}$. Bjørås and A. Klungland for providing materials.

Declaration of interest: The authors report no conflicts of interest. The authors alone are responsible for the content and writing of the paper.

\section{References}

Ånensen H, Provan F, Lian AT, Reinertsen S-HHS, Ueno Y, Matsuda A, Seeberg E, Bjelland S. 2001. Mutations induced by 5 -formyl-2'-deoxyuridine in Escherichia coli include base substitutions that can arise from mispairs of 5-formyluracil with guanine, cytosine and thymine. Mutation Research 476:99-107.

Bjelland S, Ånensen H, Knævelsrud I, Seeberg E. 2001. Cellular effects of 5-formyluracil in DNA. Mutation Research 486: $147-154$.

Bjelland S, Birkeland N-K, Benneche T, Volden G, Seeberg E. 1994. DNA glycosylase activities for thymine residues oxidized in the methyl group are functions of the AlkA enzyme in Escherichia coli. Journal of Biological Chemistry 269: 30489-30495.

Bjelland S, Eide L, Time RW, Stote R, Eftedal I, Volden G, Seeberg E. 1995. Oxidation of thymine to 5-formyluracil in DNA: Mechanisms of formation, structural implications, and base excision by human cell free extracts. Biochemistry 34:14758-14764.

Bjelland S, Seeberg E. 2003. Mutagenicity, toxicity and repair of DNA base damage induced by oxidation. Mutation Research 531:37-80.

Bjørås M, Luna L, Johnsen B, Hoff E, Haug T, Rognes T, Seeberg E. 1997. Opposite base-dependent reactions of a human base excision repair enzyme on DNA containing 7,8dihydro-8-oxoguanine and abasic sites. EMBO Journal 16: 6314-6322.

Douki T, Delatour T, Paganon F, Cadet J. 1996. Measurement of oxidative damage at pyrimidine bases in $\gamma$-irradiated DNA. Chemical Research in Toxicology 9:1145-1151.

Fujikawa K, Kamiya H, Kasai H. 1998. The mutations induced by oxidatively damaged nucleotides, 5-formyl-dUTP and 5hydroxy-dCTP, in Escherichia coli. Nucleic Acids Research $26: 4582-4587$.

Genschel J, Littman SJ, Drummond JT, Modrich P. 1998. Isolation of MutS $\beta$ from human cells and comparison of the mismatch repair specificities of MutS $\beta$ and MutS $\alpha$. Journal of Biological Chemistry 273:19895-19901.

Guex N, Peitsch MC. 1997. SWISS-MODEL and the SwissPdbViewer: An environment for comparative protein modeling. Electrophoresis 18:2714-2723.

Halliwell B, Gutteridge JMC. 1989. Free radicals in biology and medicine (2nd edition). Oxford: Clarendon Press.

Hong H, Wang Y. 2007. Derivatization with Girard reagent T combined with LC-MS/MS for the sensitive detection of 5 -formyl-2'-deoxyuridine in cellular DNA. Analytical Chemistry 79:322-326.

Kamiya H, Murata-Kamiya N, Karino N, Ueno Y, Matsuda A, Kasai H. 2002. Induction of $T \rightarrow G$ and $T \rightarrow A$ transversions by 5 -formyluracil in mammalian cells. Mutation Research 513:213-222.

Kasai H, Iida A, Yamaizumi Z, Nishimura S, Tanooka H. 1990. 5-Formyldeoxyuridine: a new type of DNA damage induced by ionizing radiation and its mutagenicity to Salmonella strain TA102. Mutation Research 243:249-253.

Katafuchi A, Nakano T, Masaoka A, Terato H, Iwai S, Hanaoka F, Ide H. 2004. Differential specificity of human and Escherichia coli endonuclease III and VIII homologues for 
oxidative base lesions. Journal of Biological Chemistry 279: 14464-14471.

Kavli B, Sundheim O, Akbari M, Otterlei $M$, Nilsen $H$, Skorpen F, Aas PA, Hagen L, Krokan HE, Slupphaug G. 2002. hUNG2 is the major repair enzyme for removal of uracil from $\mathrm{U}: \mathrm{A}$ matches, $\mathrm{U}: \mathrm{G}$ mismatches, and $\mathrm{U}$ in single-stranded DNA, with hSMUG1 as a broad specificity backup. Journal of Biological Chemistry 277:39926-39936.

Kino K, Shimizu Y, Sugasawa K, Sugiyama H, Hanaoka F. 2004. Nucleotide excision repair of 5 -formyluracil in vitro is enhanced by the presence of mismatched bases. Biochemistry 43:2682-2687.

Leiros I, Nabong MP, Grøsvik K, Ringvoll J, Haugland GT, Uldal L, Reite K, Olsbu IK, Knævelsrud I, Moe E, Andersen OA, Birkeland N-K, Ruoff P, Klungland A, Bjelland S. 2007. Structural basis for enzymatic excision of $N^{1}$-methyladenine and $N^{3}$-methylcytosine from DNA. EMBO Journal 26:2206-2217.

Lindahl T, Wood RD. 1999. Quality control by DNA repair. Science 286:1897-1905.

Liu P, Burdzy A, Sowers LC. 2003. Repair of the mutagenic DNA oxidation product, 5-formyluracil. DNA Repair 2:199-210.

Masaoka A, Matsubara M, Hasegawa R, Tanaka T, Kurisu S, Terato H, Ohyama Y, Karino N, Matsuda A, Ide H. 2003. Mammalian 5-formyluracil-DNA glycosylase. 2. Role of SMUG1 uracil-DNA glycosylase in repair of 5-formyluracil and other oxidized and deaminated base lesions. Biochemistry 42:5003-5012.

Masaoka A, Terato H, Kobayashi M, Honsho A, Ohyama Y, Ide H. 1999. Enzymatic repair of 5-formyluracil. I. Excision of 5-formyluracil site-specifically incorporated into oligonucleotide substrates by AlkA protein (Escherichia coli 3-methyladenine DNA glycosylase II). Journal of Biological Chemistry 274:25136-25143.

Matsubara M, Masaoka A, Tanaka T, Miyano T, Kato N, Terato H, Ohyama Y, Iwai S, Ide H. 2003. Mammalian 5formyluracil-DNA glycosylase. 1. Identification and characterization of a novel activity that releases 5-formyluracil from DNA. Biochemistry 42:4993-5002.

Matsubara $\mathrm{M}$, Tanaka $\mathrm{T}$, Terato $\mathrm{H}$, Ohmae $\mathrm{E}$, Izumi $\mathrm{S}$, Katayanagi K, Ide H. 2004. Mutational analysis of the damage-recognition and catalytic mechanism of human SMUG1 DNA glycosylase. Nucleic Acids Research 32: 5291-5302.

McCullough AK, Dodson ML, Lloyd RS. 1999. Initiation of base excision repair: Glycosylase mechanisms and structures. Annual Review of Biochemistry 68:255-285.
Miyabe I, Zhang Q-M, Kino K, Sugiyama H, Takao M, Yasui A, Yonei S. 2002. Identification of 5-formyluracil DNA glycosylase activity of human hNTH1 protein. Nucleic Acids Research 30:3443-3448.

Ono A, Okamoto T, Inada M, Nara H, Matsuda A. 1994. Nucleosides and nucleotides. 131. Synthesis and properties of oligonucleotides containing 5-formyl-2'-deoxyuridine. Chemical \& Pharmaceutical Bulletin (Tokyo) 42: 2231-2237.

Pettersen HS, Sundheim O, Gilljam KM, Slupphaug G, Krokan HE, Kavli B. 2007. Uracil-DNA glycosylases SMUG1 and UNG2 coordinate the initial steps of base excision repair by distinct mechanisms. Nucleic Acids Research 35: 3879-3892.

Pouget J-P, Frelon S, Ravanat J-L, Testard I, Odin F, Cadet J. 2002. Formation of modified DNA bases in cells exposed either to gamma radiation or to high-LET particles. Radiation Research 157:589-595.

Slupphaug G, Kavli B, Krokan HE. 2003. The interacting pathways for prevention and repair of oxidative DNA damage. Mutation Research 531:231-251.

Tsunoda M, Kondo J, Karino N, Ueno Y, Matsuda A, Takenaka A. 2002. Water mediated Dickerson-Drewtype crystal of DNA dodecamer containing 2'-deoxy-5formyluridine. Biophysical Chemistry 95:227-233.

Tsunoda M, Sakaue T, Naito S, Sunami T, Karino N, Ueno Y, Matsuda A, Takénaka A. 2001. X-ray analyses of DNA dodecamers containing 2'-deoxy-5-formyluridine. Nucleic Acids Research (Suppl. 1):279-280.

Volk DE, Thiviyanathan V, Somasunderam A, Gorenstein DG. 2007. Ab initio base-pairing energies of an oxidized thymine product, 5-formyluracil, with standard DNA bases at the BSSE-free DFT and MP2 theory levels. Organic \& Biomolecular Chemistry 5:1554-1558.

Wibley JEA, Waters TR, Haushalter K, Verdine GL, Pearl LH. 2003. Structure and specificity of the vertebrate antimutator uracil-DNA glycosylase SMUG1. Molecular Cell 11: $1647-1659$.

Zhang Q-M, Sugiyama H, Miyabe I, Matsuda S, Saito I, Yonei S. 1997. Replication of DNA templates containing 5formyluracil, a major oxidative lesion of thymine in DNA. Nucleic Acids Research 25:3969-3973.

Zhang Q-M, Yonekura S-I, Takao M, Yasui A, Sugiyama H, Yonei S. 2005. DNA glycosylase activities for thymine residues oxidized in the methyl group are functions of the hNEIL1 and hNTH1 enzymes in human cells. DNA Repair 4:71-79. 